\title{
AVALIAÇÃO DAS PERDAS DE ÁGUA EM SISTEMA DE ABASTECIMENTO DE ÁGUA: ESTUDO NO SETOR PARQUE DAS NAÇÕES, PARNAMIRIM/RN
}

\author{
WATER LOSSES EVALUATION ABOUT WATER SUPPLY SYSTEM: STUDY IN SECTOR \\ PARQUE DAS NAÇÕES, PARNAMIRIM/RN
}

Sansara Félix Pereiraa, Juliana Delgado Tinôcoa

a Universidade Federal do Rio Grande do Norte

sansarafelix@gmail.com, judeltinoco@gmail.com

\section{Resumo}

As perdas de água são refletidas em impactos negativos, seja à população, à companhia de abastecimento de água e mesmo ao meio ambiente. Em relação às perdas reais, o volume perdido ocorre nas etapas de produção e distribuição da água, enquanto que as perdas aparentes correspondem ao volume de água consumido que não gera faturamento à companhia, seja por ligações clandestinas, fraudes e, principalmente, por submedição nos hidrômetros. O presente artigo apresenta o estudo desenvolvido no setor Parque das Nações do sistema de abastecimento de água do município de Parnamirim/RN, com o objetivo de diagnosticar as perdas de água existentes. Para tanto, dividiu-se a área de interesse em quatro subsetores e, com base em banco de dados e estimativas, foi elaborada a matriz de balanço hídrico proposta pela International Water Association (IWA), ferramenta que permite a estratificação dos componentes de consumo e perdas de água ao longo de um sistema. De posse dos balanços hídricos finalizados para o setor Parque das Nações e respectivos subsetores, verificou-se que essas regiões exibiram cenário semelhante, no qual as perdas totalizaram mais da metade do volume de água fornecido ao sistema de abastecimento, como também as perdas reais foram maiores que as perdas aparentes.

Palavras-chave: Sistema de abastecimento de água; Balanço hídrico; Perdas reais e perdas aparentes.

\section{Abstract}

Water losses are reflected in negative impacts to the population, the water supply company and even the environment. Regarding the real losses, the lost volume occurs in the water production and distribution stages, while the apparent losses correspond to the volume of water consumed, that does not generate profit for the company, through clandestine connections, fraud and, mainly, by sub-measure in water meters. This paper presents the study developed at Parque das Nações sector of the water supply system in Parnamirim city, state of Rio Grande do Norte, Brazil; in order to diagnose the existing water losses. Therefore, the area of interest was divided into four subsectors and, based on a database and estimates, the water balance matrix proposed by the International Water Association (IWA) was elaborated, a tool that allows the stratification of the water consumption and losses components throughout a system. With the water balances for the Parque das Nações sector and its subsectors, it was found that these regions presented a similar situation, in which water losses represented more than half of the provided water volume, as well as the real losses were greater than the apparent losses.

Keywords: Water supply system; Water balance; Real losses and apparent losses. 


\section{INTRODUÇÃO}

Dado que a água é um recurso natural indispensável de caráter estruturante e estratégico para 0 desenvolvimento socioeconômico de uma região, o fornecimento de água potável, em quantidade e qualidade adequadas e pressão suficiente, constitui uma das principais prioridades para a população. Essas condições de acesso à água devem ser garantidas pelo sistema de abastecimento para consumo humano, que compreende desde a captação em mananciais, subterrâneos ou superficiais, até as ligações prediais, sendo composto por um conjunto de infraestruturas e instalações operacionais.

Diversas regiões no Brasil se encontram em um quadro de crise hídrica, poluição generalizada e, consequentemente, crescente dificuldade de disponibilidade de mananciais, principalmente superficiais, bem como de água bruta de qualidade adequada aos diversos tipos de usos e em quantidade suficiente ao atendimento da demanda. Assim, deve-se salientar a necessidade de se garantir, por parte das companhias de saneamento, eficiência operacional adequada no uso da água para abastecimento público. Essa pode ser alcançada por meio do exercício de gestão técnica destinada à execução de medidas estruturais e estruturantes de controle de perdas, cujo requisito fundamental é o pleno conhecimento dos sistemas operados, o que inclui o diagnóstico do quadro de perdas de água.

No sistema de abastecimento de água (SAA), as perdas são provenientes de várias causas, que podem ocorrer desde a unidade de captação até a entrega ao consumidor final. No entanto, as perdas apresentam maior concentração ao longo das redes de distribuição (CHEUNG et al., 2009). Em cada etapa, há condições específicas que fazem predominar um determinado tipo de perda. A maioria é originada pela inadequada gestão comercial por parte dos prestadores de serviços responsáveis pelos sistemas de abastecimento de água, como também são ocasionadas pelas operações e manutenções inexistentes ou deficientes das tubulações e instalações constituintes do sistema (TARDELLI FILHO, 2006).

As perdas inerentes a um SAA podem ser classificadas em perdas reais ou perdas aparentes e estão diretamente relacionadas à eficiência operacional e econômica da companhia de saneamento; quanto menor o volume de água perdido, menor é o custo despendido na operação. Essa relação é revertida ao consumidor final como benefício no que diz respeito à estrutura tarifária aplicada pela água consumida, dado que o volume referente às perdas hídricas é contabilizado durante a composição de preços pelo prestador de serviços públicos de abastecimento de água.

A perda real corresponde aos volumes de água que escoam através de extravasamentos verificados nos reservatórios e, predominantemente, de vazamentos ocorridos ao longo do sistema de abastecimento de água, caracterizando a parcela de água produzida pela empresa de saneamento, mas que não alcança as unidades de consumo (ABES, 2015; SERRANITO; DONNELLY, 2017). Assim, essa quantidade perdida se configura em custo de produção e transporte de água tratada (ABES, 2013; FUNASA, 2014). A ocorrência de vazamentos apresenta como causas mais frequentes a ausência de manutenção da tubulação, bem como a instalação inadequada desta, e variações de pressão na rede de distribuição de água.

Em relação às perdas reais, dois aspectos detêm significativa importância. $O$ primeiro diz respeito à conservação de recursos hídricos, uma vez que essas perdas físicas implicam na necessidade de se explorar os atuais ou novos mananciais, que já se encontram escassos. O outro está relacionado a problemas na saúde pública, visto que os pontos de vazamentos tornam o SAA mais vulnerável à contaminação da água produzida, por meio da perda de estanqueidade das tubulações e presença de juntas danificadas, facilitando a entrada de agentes nocivos após despressurização do sistema (TARDELLI FILHO, 2006).

O outro tipo de perda é denominado de perda aparente, caracterizada pelo volume de água efetivamente produzido e consumido, mas não contabilizado nem faturado pela companhia de abastecimento de água, devido à execução de fraudes, prática de ligações clandestinas, falhas do cadastro do usuário na gestão comercial da companhia e, principalmente, erros de medição nos hidrômetros (CHEUNG et al., 2009; FUNASA, 2014). Pode-se dizer, ainda, que nas perdas aparentes os custos estão relacionados ao valor pago pelo consumidor com base na política tarifária aplicada pelo prestador de serviços (TARDELLI FILHO, 2006). 
De acordo com Tsutiya (2006), a existência de tubulações antigas no sistema de abastecimento de água, que se apresentam deterioradas devido à falta de manutenção e operação adequadas, e a gestão comercial inadequada das companhias de saneamento constituem as maiores deficiências nos centros urbanos com maior dinamismo econômico e produtivo, cuja consequência é o elevado volume de água perdido, traduzido na perda de faturamento por parte do prestador dos respectivos serviços. Dessa forma, as perdas existentes em sistemas de abastecimento de água deveriam integrar a principal preocupação dessas companhias.

Segundo Tardelli Filho (2006), a existência de medidores com determinado grau de imprecisão intrínseco, bem como a presença de tubulações enterradas pressurizadas fazem com que não seja possível anular as perdas nos sistemas de abastecimento de água, mesmo que estes sejam implantados e operados de forma adequada. Assim, busca-se operar com um nível de perdas considerado aceitável. O Plano Nacional de Saneamento Básico (PLANSAB) estabelece, para 0 índice de perdas na distribuição de água na região Nordeste, a meta de 33\% para o ano de 2033 (PLANSAB, 2013).

O cenário brasileiro de perdas hídricas no setor de saneamento merece destaque, uma vez que o índice médio nacional de perdas de água na distribuição, incluindo perdas reais $e$ aparentes, é de $36,7 \%$ (SNIS, 2016). Na região Nordeste do Brasil, esse índice se apresenta superior à média nacional, com valor de 45,7\%. $\mathrm{Em}$ alguns municípios, essas perdas superam $50 \%$, como é o caso de Parnamirim/RN, cujo índice é de $52,45 \%$.

Nesse sentido, o presente trabalho teve 0 objetivo de quantificar os componentes de consumo autorizado não faturado, perdas aparentes e perdas reais de água da matriz do balanço hídrico, proposta pela International Water Association (IWA), para o SAA do setor Parque das Nações no município de Parnamirim, localizado na Região Metropolitana de Natal, no estado do Rio Grande do Norte (RN).

\section{METODOLOGIA}

\subsection{Caracterização da área de estudo}

O presente estudo contempla o cômputo do balanço hídrico de um único setor de abastecimento, denominado Parque das Nações, que integra o SAA do município de Parnamirim/RN, sendo que sua operação ocorre de forma isolada. Essa limitação decorreu da dificuldade de obtenção de dados por setores de abastecimento, em função da rede de distribuição de água ser do tipo ramificada. Os serviços de abastecimento público de água no setor Parque das Nações são operados pela Companhia de Águas e Esgotos do Rio Grande do Norte (CAERN), e esse setor é responsável pelo abastecimento dos consumidores distribuídos nos loteamentos Parque das Árvores e Caminho do Sol, no conjunto habitacional COOPHAB e nos condomínios residenciais Ecoville Condomínio Clube, Novo Leblon Condomínio Clube e Condomínio Central Park 2.

A ocupação do solo preponderante é do tipo residencial, com predominância das unidades unifamiliares de padrão socioeconômico médio e baixo. No entanto, observa-se o processo de verticalização das construções, em núcleos isolados, no loteamento Parque das Árvores e no conjunto habitacional COOPHAB.

O SAA é dotado de captação em manancial subterrâneo, especificamente no Aquífero Dunas/Barreiras, por meio de uma bateria de sete poços tubulares, em que a água de um deles é direcionada a um reservatório do tipo elevado, responsável pelo abastecimento dos condomínios, e os demais poços funcionam com injeção direta na rede de distribuição. A tecnologia de tratamento da água se restringe, exclusivamente, à etapa de desinfecção, efetuada com utilização de hipoclorito de cálcio em pastilhas, e a rede de distribuição existente está instalada com tubos de PVC.

Definida, de forma aproximada, a área abastecida por cada poço, foi possível realizar a fragmentação do setor Parque das Nações em quatro subsetores, conforme apresentado na Figura 1.

\subsection{Aquisição de dados}

As informações necessárias para o desenvolvimento deste trabalho foram obtidas, prioritariamente, de dados secundários cedidos pela CAERN, referentes ao ano de 2017.

\subsection{Aplicação da matriz do balanço hídrico}

A representação e a quantificação volumétrica de todos os possíveis usos da água ao longo de um sistema de abastecimento possuem ampla aplicação prática. Assim, no 
contexto de perdas hídricas, insere-se a sistematização do balanço hídrico como uma ferramenta técnica e gerencial, com o intuito de tornar a compreensão mais clara e objetiva dos conceitos envolvidos, sendo proposta pela IWA uma matriz que permite a estratificação dos componentes de consumo e perdas de água ao longo de um sistema, conforme modelo genérico apresentado no Quadro 1.

Figura 1: Esquema do SAA do setor Parque das Nações: localização dos poços tubulares e identificação das respectivas áreas de abastecimento

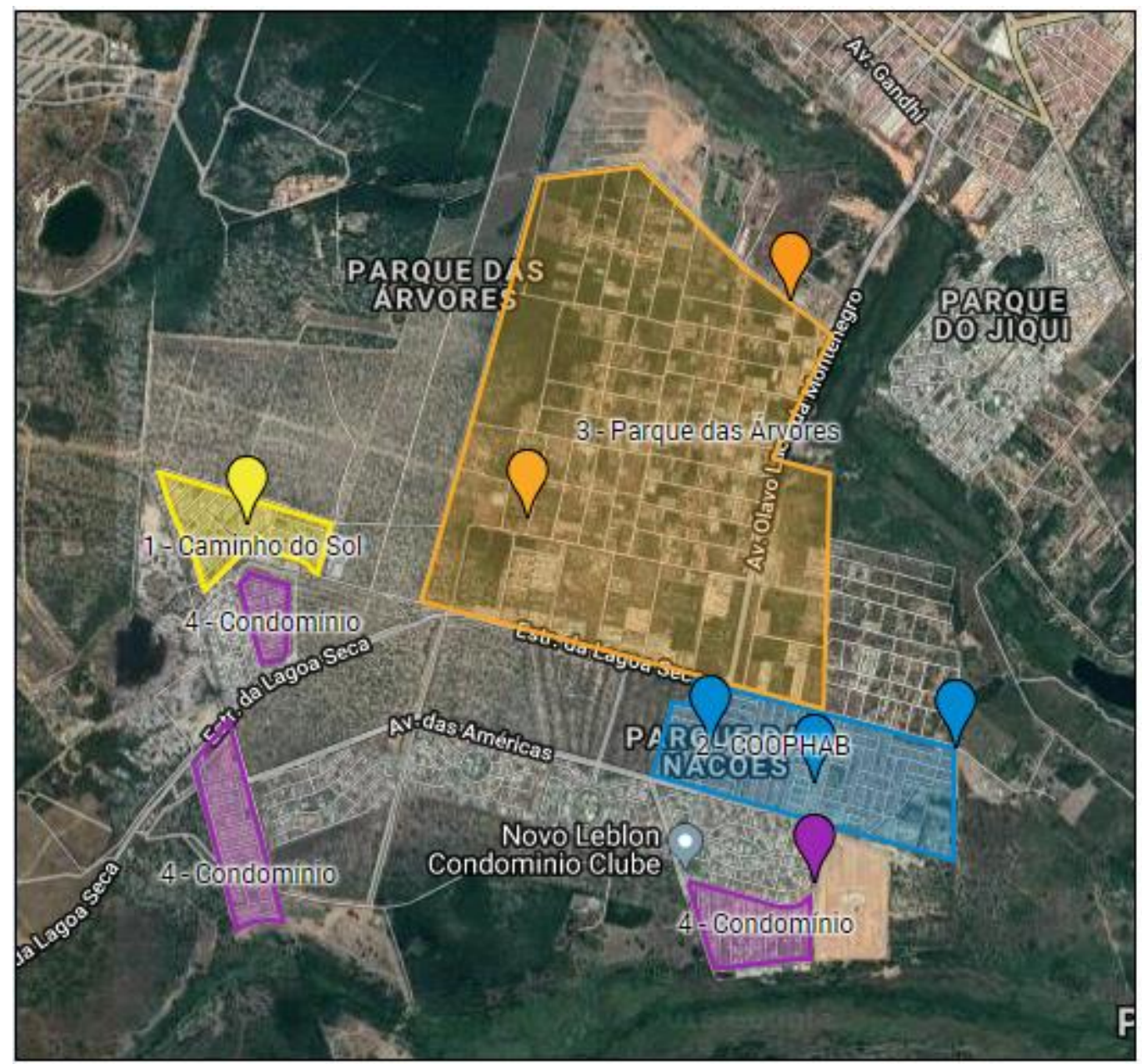

Fonte: Adaptada de Google Maps (2018).

Quadro 1: Matriz do balanço hídrico de um sistema de abastecimento de água

\begin{tabular}{|c|c|c|c|c|}
\hline \multirow{8}{*}{$\begin{array}{l}\text { Água que } \\
\text { entra no } \\
\text { sistema }\end{array}$} & \multirow{4}{*}{$\begin{array}{l}\text { Consumo } \\
\text { autorizado }\end{array}$} & \multirow{2}{*}{$\begin{array}{l}\text { Consumo autorizado } \\
\text { faturado }\end{array}$} & Consumo faturado medido & \multirow{2}{*}{$\begin{array}{l}\text { Água } \\
\text { faturada }\end{array}$} \\
\hline & & & Consumo faturado não medido & \\
\hline & & \multirow{2}{*}{$\begin{array}{l}\text { Consumo autorizado } \\
\text { não faturado }\end{array}$} & Consumo não faturado medido & \multirow{6}{*}{$\begin{array}{l}\text { Água } \\
\text { não } \\
\text { faturada }\end{array}$} \\
\hline & & & Consumo não faturado não medido & \\
\hline & \multirow{4}{*}{$\begin{array}{c}\text { Perdas de } \\
\text { água }\end{array}$} & \multirow{2}{*}{ Perdas aparentes } & Uso não autorizado & \\
\hline & & & Erros de medição & \\
\hline & & \multirow{2}{*}{ Perdas reais } & Vazamentos & \\
\hline & & & Extravasamentos & \\
\hline
\end{tabular}

Fonte: Adaptado de Alegre et al. (2006). 
Com base nas considerações da IWA, apresentam-se as definições das grandezas delineadas no balanço hídrico, cuja avaliação, geralmente, se efetua em bases anuais (AESBE, 2015c):

i) água que entra no sistema: volume total de água introduzido no sistema de abastecimento de água ou em parte deste;

ii) consumo autorizado: volume correspondente à soma do consumo autorizado faturado com o autorizado não faturado;

iii) perdas de água: volume referente à soma do volume de perdas aparentes com o de perdas reais;

iv) consumo autorizado faturado: representa os volumes medidos nos hidrômetros e os estimados nos locais onde não há instalação de hidrômetros, cuja soma corresponde ao volume refletido em faturamento para o prestador de serviços responsável pelo abastecimento de água;

v) consumo autorizado não faturado: compõe-se dos volumes medidos e não medidos, a estimar, cujo uso da água é legitimado, mesmo sem gerar receita para a companhia de saneamento;

vi) água faturada: compreende a parcela de água produzida e comercializada, traduzida no faturamento devido ao fornecimento de água ao consumidor;

vii) água não faturada: corresponde à diferença entre os totais do volume de água que entra no sistema e o consumo autorizado faturado.

Em termos volumétricos, a medição das frações constituintes do balanço hídrico, quando exequível, se efetua conforme duas esferas: macromedição e micromedição. Esta se refere à contabilização dos volumes de água fornecidos aos consumidores finais, a partir de leituras periódicas geradas nos hidrômetros instalados, tendo em vista os processos de faturamento. A macromedição é considerada a mensuração principal da matriz do balanço hídrico, cujo cômputo é relativo aos volumes produzidos em partes do sistema de abastecimento de água ou mesmo apurados em setores operacionais da rede de distribuição (ABES, 2015).

O cálculo das variáveis empregadas no balanço hídrico requer, inicialmente, a definição dos pontos de controle no SAA, para então se realizar medições, quando exequíveis, ou estimativas criteriosas, onde não há a instalação de aparelhos de medição. Cada componente da matriz do balanço hídrico, estabelecida com base nos padrões da IWA, detém incertezas provenientes de imprecisão dos valores relativos às medições, hipóteses e estimativas; assim como de erros desenvolvidos ao longo do tratamento dos dados. Essas incertezas, quando acumuladas, apresentam valores significativos, que podem ocasionar a adoção de estratégias inadequadas de redução de perdas hídricas (FANNER, 2009).

Com base nas considerações da IWA, a aplicação da técnica do balanço hídrico demanda a execução de oito (8) etapas, detalhadas a seguir e resumidas no fluxograma apresentado na Figura 2.

A primeira etapa visa identificar o volume total (base anual) de água que entra em cada subsetor (VE), resultado da soma dos volumes produzidos mensalmente pelos respectivos poços tubulares. Entretanto, apenas cinco poços apresentam dados provenientes de macromedição, os quais foram fornecidos pela CAERN (2017c). Assim, com base em dados coletados e disponibilizados pela CAERN (2017c), o volume produzido pelos demais foi estimado com base no consumo de energia elétrica do motor da bomba, medido pela Companhia Energética do Rio Grande do Norte (COSERN). Essa relação se evidencia por meio da Equação 1, na qual o peso específico assume o valor de $9,8.10^{3} \mathrm{~N} / \mathrm{m}^{3}$, aproximadamente, no caso particular da água.

$$
V=\frac{E \cdot \eta \cdot 3600}{9,8 \cdot H}
$$

Em que:

$\checkmark$ é o volume de água estimado produzido $\left(\mathrm{m}^{3}\right)$;

E é a energia elétrica consumida pelo motor da bomba (kWh);

ๆ é o coeficiente de rendimento global do conjunto elevatório (\%); e

H é a altura total de elevação da bomba (mca).

Vale ressaltar que se adotou o valor fixo de $30 \%$ para o rendimento global do conjunto motorbomba dos poços (CAERN, 2017c).

Contudo, a Equação 1 é obtida por meio do rearranjo das Equações 2, 3 e 4, encontradas em Porto (2006). 
Figura 2: Sequenciamento da metodologia proposta para aplicação da matriz do balanço hídrico em SAA

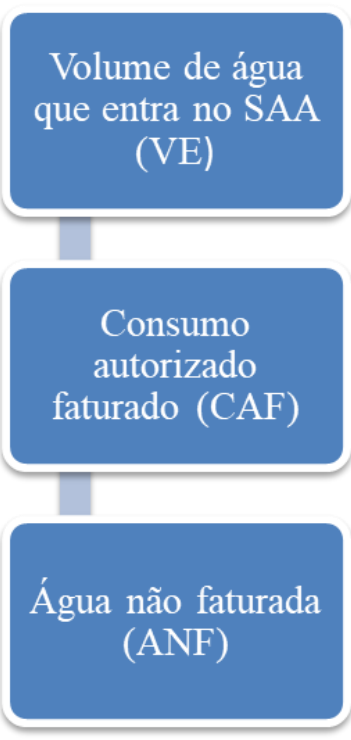

Fonte: Autores.

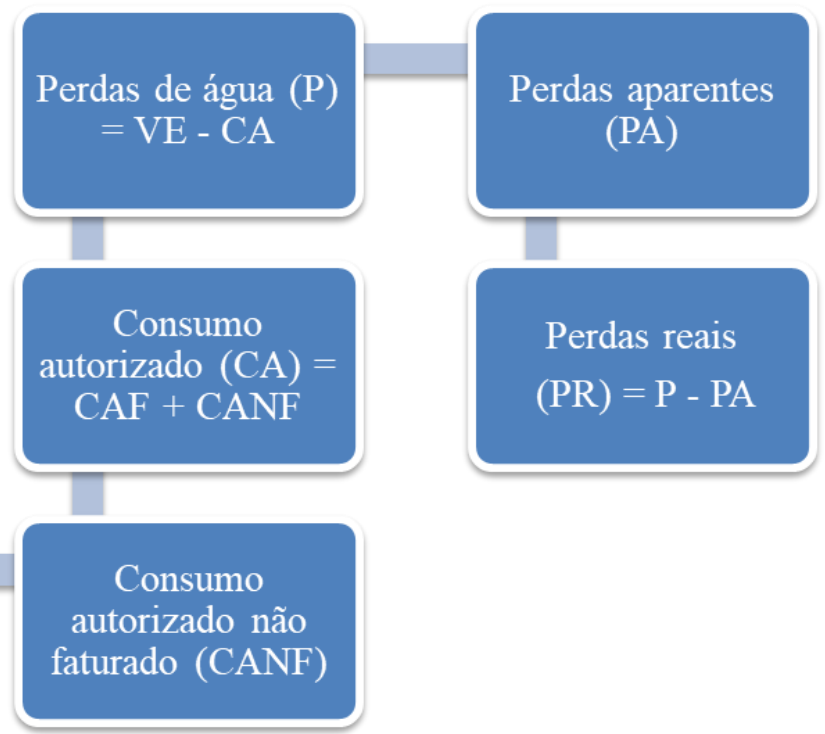

Pot $=\frac{E}{\Delta t}$

Na qual:

Pot é a potência elétrica fornecida pelo motor que aciona a bomba $(\mathrm{kW})$; e

$\Delta_{\mathrm{t}}$ é o período de tempo de funcionamento do conjunto motor-bomba (h).

$$
\mathrm{Q}=\frac{\mathrm{v}}{\Delta \mathrm{t}}
$$

Em que:

Q é a vazão de escoamento $\left(\mathrm{m}^{3} / \mathrm{s}\right)$; e

$\Delta_{\mathrm{t}}$ é o período de tempo de funcionamento do conjunto motor-bomba (s).

$$
\text { Pot }=\frac{9,8 \cdot \mathrm{Q} \cdot \mathrm{H}}{\eta}
$$

A segunda etapa consistiu em definir o consumo autorizado faturado medido (CAFM) e o consumo autorizado faturado não medido (CAFNM), cujo montante foi contabilizado como consumo autorizado faturado (CAF) e como água faturada $(\mathrm{AF})$. Os volumes mensais correspondentes às duas primeiras variáveis de consumo se apresentam na Tabela 1.

Considerando o número médio de ligações com hidrômetros e o de ligações não hidrometradas, obteve-se que o índice médio de micromedição para o setor em estudo foi de, aproximadamente, 99,5\% no ano de 2017 .

O volume não medido encontra-se estipulado, cujo faturamento se efetua segundo uma taxa fixa referente ao consumo mínimo, a qual é estabelecida pela estrutura tarifária de água da Companhia, independente do volume consumido. Dessa forma, pode haver um consumo excedente que não é faturado, uma vez que a ausência de medição apresenta como consequência o desperdício de água por parte do usuário. Deve-se ressaltar que apenas o consumo relativo às economias ativas foi contabilizado na determinação desses componentes da matriz do balanço hídrico, visto que é inviável, tecnicamente, a identificação do período no qual cada economia cortada, em determinado mês, manteve-se ativa neste.

A terceira etapa correspondeu ao cálculo do volume referente à água não faturada (ANF), que resulta da diferença entre a água que entra no subsetor (VE) e a água faturada (AF).

A quarta etapa consistiu da determinação do consumo autorizado não faturado medido (CANFM) e o consumo autorizado não faturado não medido (CANFNM), cuja soma foi computada como consumo autorizado não faturado (CANF). De acordo com a AESBE (2015b), esse componente do balanço hídrico contabiliza o consumo legítimo de água tratada relativo ao esvaziamento e limpeza da rede de distribuição para reparos, descargas de rede de distribuição para desinfecção, limpeza de reservatórios, 
desobstrução e limpeza de redes coletoras de esgotos, combate a incêndios pelo Corpo de Bombeiros, consumo nas instalações próprias da companhia de saneamento e em áreas de assentamento urbano precário, utilização de água em eventos públicos, abastecimento por chafarizes e carros pipa sem faturamento e imprecisão na estimativa do consumo diante da ausência de hidrômetros. Vale ressaltar que apenas o último tipo de consumo foi identificado no SAA em estudo. Além disso, a CAERN não dispõe de dados concernentes a esses volumes de água em consequência, principalmente, da ausência de medição dos mesmos, fazendo com que sejam conhecidos por meio de estimativas, ainda não efetuadas pela Companhia para o setor Parque das Nações.

Tabela 1: Quantidade de economias ativas de água e volume de água faturado medido e não medido mensalmente, para o setor

Parque das Nações

\begin{tabular}{|c|c|c|c|}
\hline Mês & $\begin{array}{l}\text { Indicador } \\
\text { hidrômetro }\end{array}$ & $\begin{array}{c}\text { Quantidade de } \\
\text { economias ativas } \\
\text { de água }\end{array}$ & $\begin{array}{l}\text { Volume de água } \\
\text { faturado }\left(\mathrm{m}^{3}\right)\end{array}$ \\
\hline \multirow{2}{*}{ Janeiro } & COM & 2.461 & 37.976 \\
\hline & SEM & 7 & 1.913 \\
\hline \multirow{2}{*}{ Fevereiro } & COM & 2.483 & 37.772 \\
\hline & SEM & 7 & 1.564 \\
\hline \multirow{2}{*}{ Março } & COM & 2.481 & 39.546 \\
\hline & SEM & 7 & 1.584 \\
\hline \multirow{2}{*}{ Abril } & COM & 2.472 & 32.634 \\
\hline & SEM & 7 & 1.238 \\
\hline \multirow{2}{*}{ Maio } & COM & 2.470 & 37.273 \\
\hline & SEM & 9 & 740 \\
\hline \multirow{2}{*}{ Junho } & COM & 2.484 & 38.741 \\
\hline & SEM & 9 & 953 \\
\hline \multirow{2}{*}{ Julho } & COM & 2.490 & 36.015 \\
\hline & SEM & 9 & 1.218 \\
\hline \multirow{2}{*}{ Agosto } & COM & 2.490 & 35.392 \\
\hline & SEM & 9 & 1.205 \\
\hline \multirow{2}{*}{ Setembro } & COM & 2.481 & 37.559 \\
\hline & SEM & 8 & 1.472 \\
\hline \multirow{2}{*}{ Outubro } & COM & 2.497 & 36.588 \\
\hline & SEM & 2 & 599 \\
\hline \multirow{2}{*}{ Novembro } & COM & 2.527 & 38.304 \\
\hline & SEM & 8 & 70 \\
\hline \multirow{2}{*}{ Dezembro } & COM & 2.539 & 41.007 \\
\hline & SEM & 9 & 70 \\
\hline
\end{tabular}

Fonte: CAERN (2017a).

Nesse estudo, o CANF se restringiu ao volume referente à imprecisão na estimativa do consumo diante da ausência de hidrômetros. Para obtenção desse valor, determinou-se, mensalmente, o consumo médio por economia com hidrômetro, por meio da razão entre 0 volume faturado correspondente às economias ativas medidas e a quantidade destas. O mesmo procedimento foi realizado para as economias ativas sem hidrômetros. Assim, estipulou-se a média de consumo mensal por economia sem hidrômetro. Essas relações se evidenciam por 
meio das Equações 5 e 6 .

$$
\mathrm{CEH}=\frac{\mathrm{VFEH}}{\mathrm{EH}}
$$

Na qual:

$\mathrm{CEH}$ é o consumo médio mensal por economia com hidrômetro $\left(\mathrm{m}^{3}\right)$;

VFEH é o volume faturado mensal referente às economias ativas medidas $\left(\mathrm{m}^{3}\right) ; \mathrm{e}$

EH é o número de economias ativas com hidrômetro.

$$
\mathrm{CE}=\frac{\mathrm{VFE}}{\mathrm{E}}
$$

Em que:

CE é o consumo médio mensal por economia sem hidrômetro $\left(\mathrm{m}^{3}\right)$;

VFE é o volume faturado mensal referente às economias ativas não medidas $\left(\mathrm{m}^{3}\right)$; e

E é o número de economias ativas sem hidrômetro.

Segundo metodologia proposta pela AESBE (2015d), quando o consumo médio mensal por economia com hidrômetro for superior à média de consumo mensal por economia sem hidrômetro, a diferença entre ambos deve ser multiplicada pela quantidade mensal de economias ativas não medidas. Esse produto representa o CANF mensal, conforme a Equação 7.

$$
\mathrm{CEH}>\mathrm{CE} \rightarrow \mathrm{CANF}_{\text {mensal }}=(\mathrm{CEH}-\mathrm{CE}) \cdot \mathrm{E}
$$

Por fim, a soma desses produtos foi registrada como o volume anual relativo ao CANF no período analisado.

A quinta etapa correspondeu ao cálculo do volume relativo ao consumo autorizado (CA), resultante da soma do consumo autorizado faturado (CAF) com o consumo autorizado não faturado (CANF).

A sexta etapa determinou as perdas de água $(\mathrm{P})$, subtraindo o consumo autorizado $(\mathrm{CA})$ à água que entra no SAA (VE).

A sétima etapa consistiu em estimar o volume correspondente às perdas aparentes (PA), divididas em uso não autorizado (UNA), sendo este oriundo das fraudes, ligações clandestinas e falhas de cadastro existentes no sistema em estudo, e volume não medido referente à submedição (SUB) dos hidrômetros instalados.

Para estimar o volume de água referente ao consumo não autorizado, identificou-se, conforme o estudo desenvolvido por Nascimento e Duarte (2017), uma prática de fiscalização realizada no segundo semestre de 2016 pelo setor comercial da CAERN sobre, aproximadamente, 700 consumidores situados no município de Macaíba no estado do RN, onde se constatou que havia $57 \%$ de ligações à revelia, bem como estas apresentavam irregularidades. Assim, esse percentual foi aplicado à quantidade de ligações passíveis, no setor de interesse, de se encontrarem nas mesmas condições, em que esta é resultado da diferença entre as ligações cadastradas de água e as ligações ativas. Em seguida, determinou-se mensalmente o consumo médio por ligação ativa medida por meio da razão entre 0 volume faturado correspondente às ligações ativas medidas e a quantidade destas. Essa relação se evidencia por meio da Equação 8.

$$
\mathrm{CLH}=\frac{\text { VFLH }}{\mathrm{LH}}
$$

Na qual:

CLH é o consumo médio mensal por ligação ativa com hidrômetro $\left(\mathrm{m}^{3}\right)$;

VFLH é o volume faturado mensal referente às ligações ativas medidas $\left(\mathrm{m}^{3}\right)$; e

LH é o número de ligações ativas com hidrômetro.

Em seguida, conforme a Equação 9, o quantitativo referente às ligações não autorizadas foi multiplicado pelo consumo médio mensal por ligação ativa medida, dado que o volume consumido relativo às ligações não medidas é calculado por meio de estimativas. Esse produto representa o UNA mensal, conforme a Equação 9.

$$
\text { UNA }_{\text {mensal }}=\frac{57}{100} \cdot(\mathrm{LC}-\mathrm{LA}) \cdot \mathrm{CLH}
$$

Em que:

LC é o número de ligações cadastradas de água; e LA é o número de ligações ativas.

Por último, a soma desses produtos foi contabilizada como o volume de água anual correspondente ao uso não autorizado no setor Parque das Nações. 
Segundo Fonseca e Coelho (2009), as perdas hídricas provocadas pela submedição dos hidrômetros variam entre $10 \%$ e $30 \%$ do volume consumido pelos usuários. A submedição pode ser ocasionada por diversos fatores, como o dimensionamento inadequado e a posição de instalação do hidrômetro, o perfil de consumo dos usuários, a qualidade e velocidade da água e condições ambientais e climáticas (ARREGUI et al., 2006; THORNTON; RIZZO, 2002). De acordo com Depexe e Gasparini (2012), outro fator muito importante é o desgaste natural do hidrômetro.

No presente contexto, a metodologia mais adequada para a determinação das imprecisões de medição de um parque de hidrômetros, instalados em um dado sistema, deve estar baseada na realização de ensaios com amostras próprias e representativas do setor em estudo, como também em dados reais obtidos de levantamentos de perfil de consumo de água da população abastecida. No entanto, essa solução nem sempre é exequível, seja por razões operacionais, financeiras ou mesmo devido ao tempo despendido para execução das atividades.

A estimativa do volume de água não medido devido à inexatidão nos hidrômetros pode ser efetuada por meio do índice de submedição, definido como a porcentagem do volume fornecido aos consumidores medidos, mas que não é registrada pelos medidores, cuja determinação foi apresentada no trabalho desenvolvido por Sanchez, Motta e Alves (2000) na cidade de Juazeiro no estado da Bahia, e realizada em função do tempo de instalação dos hidrômetros. A abordagem proposta pelo estudo foi demonstrada a partir do levantamento das vazões de operação de consumidores residenciais típicos e da análise das condições reais dos hidrômetros instalados na cidade quanto aos erros de indicação.

Os resultados obtidos para os índices de submedição estão apresentados na Tabela 2, estratificados por faixa de tempo de instalação do hidrômetro e por categoria de consumo mensal dos usuários monitorados pelo estudo.

Analisando-se os índices de submedição apresentados na Tabela 2, pode-se verificar que a submedição se concentra na faixa com menor consumo mensal, e que os medidores utilizados no município de Juazeiro/BA perderam uma parcela considerável de sua exatidão poucos anos após sua instalação.

O volume de água relativo à perda progressiva de exatidão dos hidrômetros, em função do tempo de instalação, foi determinado com base no Relatório de Hidrômetros por Idade, apresentado na Tabela 3.

Tabela 2: Índices de submedição de hidrômetros (\%), considerando categorias de consumo estratificadas

\begin{tabular}{lccccc}
\hline \multirow{2}{*}{$\begin{array}{c}\text { Tempo de } \\
\text { instalação (anos) }\end{array}$} & \multicolumn{5}{c}{ Consumo mensal $\left(\mathbf{m}^{3}\right)$} \\
\cline { 2 - 6 } & Mínimo de 5 & Entre 8 e 17 & Entre 17 e 24 & Entre 47 e 56 & Máximo de 75 \\
\hline medidores novos & 37,5 & 9,5 & 5,2 & 3,2 & 1,2 \\
0 a 5 & 62,5 & 28,6 & 23 & 15,2 & 5,9 \\
5 a 10 & 65,6 & 31,8 & 25,7 & 17,2 & 4,7 \\
acima de 10 & 54 & 15,5 & 15,5 & 9,5 & 0,3 \\
\hline
\end{tabular}

Fonte: Adaptada de Sanchez, Motta e Alves (2000).

Tabela 3: Percentual de hidrômetros instalados, no setor Parque das Nações, de acordo com a faixa de idade do hidrômetro

Tempo de instalação do hidrômetro

\begin{tabular}{cc}
\hline Até 5 anos & 84,65 \\
de 6 a 10 anos & 14,90 \\
mais de 10 anos & 0,45 \\
\hline
\end{tabular}

Fonte: CAERN (2017b). 
Em seguida, aplicaram-se esses percentuais aos dados mensais fornecidos pelo banco de dados para o setor em estudo, obtendo-se os quantitativos correspondentes. Para o índice de submedição, consideraram-se os valores encontrados por Sanchez, Motta e Alves (2000), que estão apresentados na Tabela 2. Assim, de posse do volume micromedido anualmente e o percentual de submedição por faixa de idade dos hidrômetros, foi possível efetuar o cálculo do volume de água entregue ao consumidor por meio da Equação 10 (AESBE, 2015a):

$$
\mathrm{VC}=\frac{\mathrm{VM}}{(100-\mathrm{S}) / 100}
$$

Em que:

VC é o volume de água consumido $\left(\mathrm{m}^{3}\right)$;

VM é o volume micromedido $\left(\mathrm{m}^{3}\right)$; e

S é o índice de submedição (\%).

Desse modo, determinou-se o volume de água referente à submedição dos hidrômetros, obtido pela diferença entre o volume consumido e o micromedido.

A última etapa compreendeu o cálculo, de forma indireta, do volume concernente às perdas reais (PR), cujo valor é resultado da diferença entre as perdas de água $(P)$ e as perdas aparentes (PA).

Com o intuito de se comparar as perdas reais e aparentes ocorridas nos subsetores, a segunda, quarta e sétima etapas foram executadas inicialmente para o setor Parque das Nações. Em seguida, com base em uma proporção direta entre a área de fato ocupada pelo setor Parque e a área efetivamente construída em cada subsetor, determinaram-se os componentes CAF (CAFM + CAFNM), CANF e PA (UNA + SUB) da matriz do balanço hídrico para os subsetores 1, 2, 3 e 4 .

A proporção de área construída entre o setor em estudo e cada subsetor está apresentada na Tabela 4, na qual a área medida compreende área construída horizontalmente, como também terrenos não edificados, ruas e avenidas.

Tabela 4: Área medida, taxa de adensamento, área construída e proporção de área construída dos subsetores 1, 2, 3 e 4

\begin{tabular}{ccccc}
\hline Subsetor & $\begin{array}{c}\text { Área medida } \\
\text { (ha) }\end{array}$ & $\begin{array}{c}\text { Taxa de } \\
\text { adensamento }\end{array}$ & $\begin{array}{c}\text { Área } \\
\text { construída } \\
\text { (ha) }\end{array}$ & $\begin{array}{c}\text { Proporção de } \\
\text { área construída } \\
\text { subsetor/setor }\end{array}$ \\
\hline 1 & 20,7 & $90 \%$ & 18,6 & $10 \%$ \\
2 & 53,8 & $150 \%$ & 80,7 & $44 \%$ \\
3 & 295,0 & $25 \%$ & 73,8 & $40 \%$ \\
4 & 32,0 & $30 \%$ & 9,6 & $6 \%$ \\
\hline \multicolumn{5}{r}{} \\
\hline
\end{tabular}

Fonte: Autores.

A taxa de adensamento foi estipulada com auxílio de imagens de satélite da ferramenta Google Maps, para então se estabelecer a área construída total (horizontal e vertical) de cada subsetor, que se compõe do produto entre a área medida e a respectiva taxa de adensamento. Conforme a Tabela 4, o subsetor 2 apresenta taxa de adensamento superior a 100\%, uma vez que nessa área já se verifica um processo desenvolvido de verticalização das construções.

\section{RESULTADOS}

No Quadro 2, apresentam-se os volumes componentes do balanço hídrico do SAA do setor
Parque das Nações, em Parnamirim/RN, para o ano de 2017.

Identificou-se, com base no balanço hídrico computado e demonstrado no Quadro 2, que as perdas totais representam, aproximadamente, $53 \%$ do volume de água destinado ao sistema de abastecimento, valor este próximo ao percentual estimado para o município de Parnamirim/RN, que foi de 52,45\% (SNIS, 2016). Além disso, constatou-se que as perdas reais (61\%) se sobrepõem, significativamente, às perdas aparentes (39\%). Adotando-se o consumo diário de água per capita para Parnamirim/RN igual a 129,6 litros (SNIS, 2016), o volume anual referente às perdas reais do SAA em análise 
seria suficiente para abastecer uma população de, aproximadamente, 7.000 habitantes. Deste modo, considerando que as perdas reais correspondem, principalmente, ao volume de água perdido em vazamentos, os gestores da companhia de saneamento devem priorizar a prática de medidas destinadas ao controle e redução das perdas reais, como a manutenção adequada das tubulações, controle e detecção de vazamentos, bem como qualidade e rapidez no reparo, além de monitoramento da pressão na rede de distribuição de água.

Quadro 2: Balanço hídrico volumétrico $\left(\mathrm{em} \mathrm{m}^{3}\right)$ do SAA do setor

Parque das Nações no ano de 2017

\begin{tabular}{|c|c|c|c|c|}
\hline \multirow{7}{*}{$\begin{array}{c}\text { VE } \\
1.000 .626\end{array}$} & \multirow{4}{*}{$\begin{array}{c}\text { CA } \\
461.289\end{array}$} & \multirow{2}{*}{$\begin{array}{c}\text { CAF } \\
461.163\end{array}$} & $\begin{array}{c}\text { CAFM } \\
448.537\end{array}$ & \multirow{2}{*}{$\begin{array}{c}\text { AF } \\
461.163\end{array}$} \\
\hline & & & $\begin{array}{c}\text { CAFNM } \\
12.626\end{array}$ & \\
\hline & & \multirow{2}{*}{$\begin{array}{c}\text { CANF } \\
126\end{array}$} & $\begin{array}{c}\text { CANFM } \\
0\end{array}$ & \multirow{5}{*}{$\begin{array}{c}\text { ANF } \\
539.463\end{array}$} \\
\hline & & & $\begin{array}{c}\text { CANFNM } \\
126\end{array}$ & \\
\hline & \multirow{3}{*}{$\begin{array}{c}\mathbf{P} \\
539.337\end{array}$} & \multirow{2}{*}{$\begin{array}{c}\text { PA } \\
207.856\end{array}$} & $\begin{array}{c}\text { UNA } \\
23.696\end{array}$ & \\
\hline & & & $\begin{array}{c}\text { SUB } \\
184.160\end{array}$ & \\
\hline & & \multicolumn{2}{|c|}{$\begin{array}{c}\text { PR } \\
331.481\end{array}$} & \\
\hline
\end{tabular}

Fonte: Autores.

VE - Volume de entrada no sistema; CA - Consumo autorizado; P Perdas de água; CAF - Consumo autorizado faturado; CANF - Consumo autorizado não faturado; PA - Perdas aparentes; PR - Perdas reais; CAFM - Consumo autorizado faturado medido; CAFNM - Consumo autorizado faturado não medido; CANFM - Consumo autorizado não faturado medido; CANFNM - Consumo autorizado não faturado não medido; UNA - Uso não autorizado; SUB - Submedição dos hidrômetros; AF - Água faturada; ANF - Água não faturada.

Considerando apenas as perdas aparentes, a submedição dos hidrômetros merece maior destaque em detrimento ao uso não autorizado, com percentuais de $89 \%$ e $11 \%$, respectivamente. Neste sentido, propõe-se 0 investimento na substituição de hidrômetros, com o intuito de se manter a idade do parque inferior a cinco (5) anos e, dessa forma, reduzir o impacto financeiro ocasionado pela submedição para o prestador de serviços do SAA.

Em relação ao consumo autorizado não faturado, verificou-se que este apresentou volume de $126 \mathrm{~m}^{3}$ para 0 ano de 2017, valor insignificante quando comparado ao referente à água fornecida ao SAA em estudo $\left(1.000 .626 \mathrm{~m}^{3}\right)$, o que é justificado pela identificação e contabilização apenas da imprecisão na estimativa do consumo diante da ausência de hidrômetros. Além disso, consequência da inexistência de dados relacionados, o CANF foi calculado com base em estimativas, cujas incertezas podem expressar valores significativos. Isto posto, recomenda-se que os consumos relacionados a esse componente do balanço hídrico, passíveis de medição, sejam obtidos por meio da instalação de medidores.

$\mathrm{Na}$ Tabela 5, apresentam-se as perdas reais e as perdas aparentes referentes ao uso não autorizado e à submedição do setor Parque das Nações e subsetores 1, 2, 3 e 4, relativas ao ano de 2017.

Integralizada a estratificação das perdas de água nos subsetores, constatou-se semelhança entre o cenário retratado por estes e o verificado no setor Parque das Nações, no qual o volume concernente às perdas reais se apresenta superior ao referente às perdas aparentes, e, dentre estas, o volume relativo à submedição se sobrepõe ao consumo não autorizado. Dessa forma, conclui-se que o elevado volume de 
perdas hídricas não se resume a uma área isolada, mas se considera como um aspecto negativo do SAA em sua totalidade. Esta similaridade pode estar fundamentada na metodologia de estimativa adotada, realizada com base na área construída, uma vez que esta supõe semelhante o consumo de água por economia em cada subsetor, como também 0 índice de micromedição, fazendo com que as particularidades da realidade de cada área não sejam contempladas.

Tabela 5: Perdas hídricas do SAA do setor Parque das Nações e dos seus subsetores, referentes ao ano de 2017: em volume $\left(\mathrm{m}^{3}\right)$ e em

porcentagem

\begin{tabular}{ccccc}
\hline \multirow{2}{*}{ Subsetor } & Perdas reais & \multicolumn{2}{c}{ Perdas aparentes } & Perdas \\
\cline { 3 - 4 } & & $\begin{array}{c}\text { Uso não } \\
\text { autorizado }\end{array}$ & Submedição & totais \\
\hline $\begin{array}{c}\text { Parque das } \\
\text { Nações }\end{array}$ & 331.481 & 23.696 & 184.160 & 539.337 \\
\hline 1 & $33 \%$ & $2 \%$ & $18 \%$ & $54 \%$ \\
\hline \multirow{2}{*}{2} & 29.492 & 2.370 & 18.416 & 50.277 \\
& $31 \%$ & $2 \%$ & $19 \%$ & $52 \%$ \\
\hline 3 & 154.356 & 10.426 & 81.030 & 245.813 \\
& $34 \%$ & $2 \%$ & $18 \%$ & $55 \%$ \\
\hline \multirow{2}{*}{4} & 317.614 & 9.478 & 73.664 & 200.756 \\
& 30.019 & $2 \%$ & $19 \%$ & $52 \%$ \\
\hline
\end{tabular}

Fonte: Autores.

\section{CONCLUSÃO}

É difícil identificar algum legado positivo de uma crise hídrica bastante evidenciada e onerosa, assim, a efetivação de medidas sustentáveis, sobretudo no que diz respeito à água, faz-se necessária. E o combate às perdas hídricas deve se tornar prioridade nacional. Propõe-se, portanto, a elaboração e execução de um programa de controle e redução de perdas hídricas, viabilizando-se resultados que além de benefícios econômico-financeiros, proporcionam maior eficiência na gestão da demanda de água, pela via de sua redução, minimizando, sobretudo, os impactos socioambientais.

A macromedição, juntamente com a setorização do sistema de abastecimento de água são imprescindíveis para a aplicação adequada das ferramentas disponíveis para a avaliação de perdas hídricas, como é o caso do método baseado no balanço hídrico. Por sua vez, o balanço hídrico e a estratificação das perdas reais e perdas aparentes são considerados condicionantes para que o programa de controle e redução de perdas hídricas seja bem sucedido.
Portanto, a primeira recomendação para o sistema de abastecimento de água em estudo é a fragmentação da rede de distribuição em setores com fronteiras conhecidas e delimitadas adequadamente, em que as vazões referentes à entrada e à saída sejam medidas e controladas.

Desse modo, o prestador de serviços do SAA em estudo está possibilitado a estabelecer as medidas efetivas mais adequadas no combate às perdas hídricas, como também uma proporção representativa entre as mesmas, concentrando esforços nas ações destinadas ao controle e redução das perdas reais e perdas aparentes por submedição do parque de hidrômetros, uma vez que estas indicaram os maiores percentuais das perdas totais. Essa consideração se aplica aos subsetores 1, 2, 3 e 4 analisados, uma vez que apresentaram resultados semelhantes para a matriz do balanço hídrico.

Os dados estimados da matriz de balanço hídrico, passíveis de medição, devem ser obtidos por meio da instalação de aparelhos de medição, notadamente os volumes de entrada nos setores de abastecimento, uma vez que estes são a grandeza de maior porte no balanço hídrico, cuja 
mensuração é considerada como um fator crítico para a confiabilidade dos resultados.

O método adotado para o cálculo do balanço hídrico, no qual as perdas reais são determinadas por meio da diferença entre as perdas totais e as perdas aparentes, proporciona às perdas reais a propagação das incertezas das demais variáveis da matriz. Portanto, as perdas reais tendem a apresentar valores superestimados, enquanto que as perdas aparentes, volumes subestimados. Dessa forma, sugere-se o emprego de método destinado à determinação direta do volume de água referente às perdas reais, para então confrontá-lo com o resultado obtido de forma indireta.

\section{AGRADECIMENTOS}

Os autores expressam seu agradecimento à Companhia de Águas e Esgotos do Rio Grande do Norte (CAERN), em especial aos Técnicos de Engenharia Bruno Silva Mendes, Rodrigo Melo do Nascimento e Rivanilson Andrade de Lima, e ao Coordenador Comercial da Regional Agreste Trairi Joab Soares Lima, pelo fornecimento de dados e informações indispensáveis ao desenvolvimento do estudo.

\section{REFERÊNCIAS}

1. ALEGRE, H.; BAPTISTA, J. M.; CABRERA, E.; CUBILLO, F.; DUARTE, P.; HIRNER, W.; MERKEL, W.; PARENA, R. Performance Indicators for Water Supply Services: manual of best practice. 2. ed. London: IWA Publishing, 2006.

2. ARREGUI, F. J.; CABRERA, E.; COBACHO, R.; GARCÍA-SERRA J. Reducing apparent loses caused by meters inaccuracies. Water Practice \& Technology., v. 1, n. 4, p. 227-235, 2006.

3. ASSOCIAÇÃO BRASILEIRA DAS EMPRESAS ESTADUAIS DE SANEAMENTO (AESBE). Guia prático de procedimentos para estimativa de submedição no parque de hidrômetros. In: AESBE. Série balanço hídrico. Brasília: AESBE, 2015a. v. 3. Disponível em: $<h t t p: / / w w w . a e s b e . o r g . b r / g u i a s \_p r a t i c o s />$. Acesso em: 8 jun. 2018.

4. Guia prático para determinação de consumos autorizados não faturados. In: AESBE. Série balanço hídrico. Brasília: AESBE, 2015b. v. 2. Disponível em: $<$ http://www.aesbe.org.br/guias_praticos/>. Acesso em: 8 jun. 2018.
5. Guia prático para determinação de volume de entrada nos sistemas de abastecimento. In: AESBE. Série balanço hídrico. Brasília: AESBE, 2015c. v. 1. Disponível em: <http://www.aesbe.org.br/guias_praticos/>. Acesso em: 7 jun. 2018.

6. Guia prático para quantificação de balanços hídricos e indicadores de desempenho operacional. In: AESBE. Série balanço hídrico. Brasília: AESBE, 2015d. v. 5. Disponível em: $<$ http://www.aesbe.org.br/guias_praticos/>. Acesso em: 10 jun. 2018.

7. ASSOCIAÇÃO BRASILEIRA DE ENGENHARIA SANITÁRIA E AMBIENTAL (ABES). Controle e redução de perdas nos sistemas públicos de abastecimento de água: posicionamento e contribuições técnicas da ABES. Rio de Janeiro: ABES, 2015. Disponível em: <http://abesdn.org.br/pdf/28Cbesa/Perdas_Abes.pdf>. Acesso em: 18 jul. 2018.

8. Perdas em sistemas de abastecimento de água: diagnóstico, potencial de ganhos com sua redução e propostas de medidas para o efetivo combate. Rio de Janeiro: ABES, 2013. Disponível em: $<\mathrm{http}: / /$ www.abes-sp.org.br/arquivos/perdas.pdf>.

Acesso em: 26 jul. 2018.

9. CHEUNG, P. B.; KIPERSTOK, A.; COHIM, E.; ALVES, W. C.; PHILIPPI, L. S.; ZANELLA, L.; ABE, N.; GOMES, H. P.; SILVA, B. C. da; PERTEL, M.; GONÇALVES, R. F. Consumo de água. In: GONÇALVES, R. F. (Coord.). Conservação de água e energia em sistemas prediais e públicos de abastecimento de água. Rio de Janeiro: ABES, 2009. p. 36-98.

10. COMPANHIA DE ÁGUAS E ESGOTOS DO RIO GRANDE DO NORTE (CAERN). Regional Agreste Trairi. Ficha de informação sobre quantidade de ligações e economias de água cadastradas e volume de água faturado. Parnamirim, 2017a. Não publicado.

11. Regional Agreste Trairi. Relatório de Hidrômetros por Idade. Parnamirim, 2017b. Não publicado.

12. _ Unidade de Operação e Manutenção de Águas do Interior do Litoral Sul. Dados operacionais de poços tubulares. Parnamirim, 2017c. Não publicado.

13. DEPEXE, M. D.; GASPARINI, R. R. Determinação de taxas anuais de redução da eficiência da medição de hidrômetros. In: ENCONTRO TÉCNICO AESABESP, 23., 2012, São Paulo. Anais... São Paulo: SABESP, 2012. 
14. FANNER, P. V. Determining a validated water balance in an unmeasured system and understanding unmeasured residential customer consumption. In: PROCEEDINGS OF IWA SPECIALIZED CONFERENCE: WATER LOSS, 2009, Cape Town, South Africa.

15. FONSECA, P.; COELHO, A. C. Manutenção de hidrômetros - um problema econômico. In: CONGRESSO BRASILEIRO DE ENGENHARIA SANITÁRIA E AMBIENTAL, 25., 2009, Recife. Anais... Rio de Janeiro: ABES, 2009.

16. FUNDAÇÃO NACIONAL DE SAÚDE (FUNASA). Redução de perdas em sistemas de abastecimento de água. 2. ed. Brasília: FUNASA, 2014. Disponível em: $<$ http://www.funasa.gov.br/site/wpcontent/files_mf/reducao_de_perdas_em_saa74.pdf>. Acesso em: 20 jul. 2018.

17. NASCiMENTO, R. M. do; DuARTE, M. A. C. Diagnóstico técnico das perdas hídricas e financeiras no sistema de abastecimento de água de Macaíba/RN. 2017. Trabalho de Conclusão de Curso (Especialização em Gestão Ambiental) - Instituto Federal, Ciência e Tecnologia do Rio Grande do Norte, Natal, 2017.

18. PLANO NACIONAL DE SANEAMENTO BÁSICO (PLANSAB). Metas de curto, médio e longo prazos. Brasília, 2013. p. 118-127. Disponível em: <http://www.urbanismo.mppr.mp.br/arquivos/File/plansa b_texto_aprovado.pdf>. Acesso em: 16 set. 2018.

19. PORTO, R. M. Conceitos básicos. In: PORTO, R. M. Hidraúlica básica. 4. ed. São Paulo: EESC-USP, 2006. p. 3-26.
20. SANCHEZ, J. G.; MOTTA, S. A.; ALVES, W. C. Estimativa de volume de água não medido em ligações residenciais por perda de exatidão nos hidrômetros, na cidade de Juazeiro-BA. In: CONGRESSO INTERAMERICANO DE ENGENHARIA SANITÁRIA E AMBIENTAL, 27., 2000, Porto Alegre. Anais... Rio de Janeiro: ABES, 2000.

21. SERRANITO, F. S.; DONNELLY, A. Controlo ativo de perdas de água. 2. ed. Lisboa: Empresa Portuguesa das Águas Livres (EPAL), 2017.

22. SISTEMA NACIONAL DE INFORMAÇÕES SOBRE SANEAMENTO (SNIS). Série histórica Água e Esgotos. 2016. Disponível em: <http://app3.cidades.gov.br/serieHistorica/>. Acesso em: 15 mai. 2018.

23. TARDELLI FILHO, J. Controle e redução de perdas. In: TSUTIYA, M. T. Abastecimento de água. 4. ed. São Paulo: Departamento de Engenharia Hidráulica e Sanitária da Escola Politécnica da Universidade de São Paulo, 2006. p. 457-525.

24. THORNTON, J.; RIZZO, A. Apparent losses, how low can you go? In: PROCEEDINGS OF LEAKAGE MANAGEMENT CONFERENCE, 2002, Lemesos, Cyprus.

25. TSUTIYA, M. T. Concepção de sistemas de abastecimento de água. In: TSUTIYA, M. T. Abastecimento de água. 4. ed. São Paulo: Departamento de Engenharia Hidráulica e Sanitária da Escola Politécnica da Universidade de São Paulo, 2006. p. 10-34. 